\title{
Exploring subjective career success using the Kaleidoscope Career Model
}

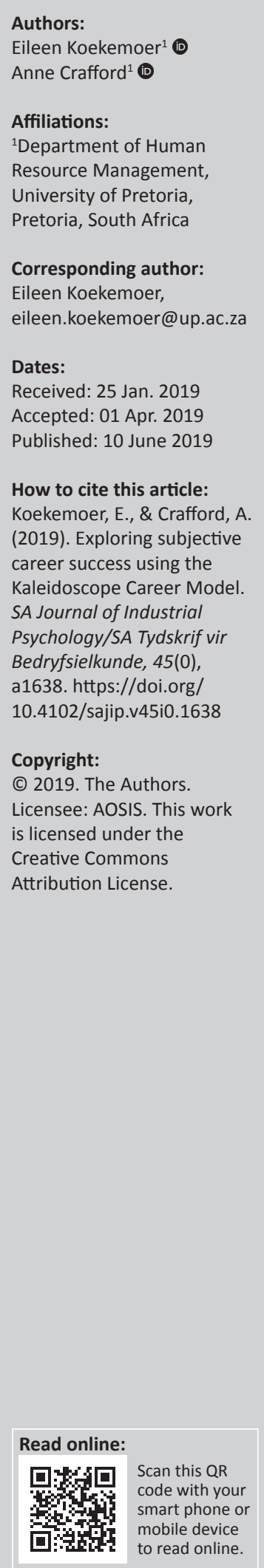

Orientation: Currently, the workplace consists of four different generations of employees, of which the youngest, Generation Y (Gen Y), will become more prevalent in the next few years. Therefore, attracting and retaining employees of this generation are essential for organisations.

Research purpose: The aim of the present study was to investigate how Gen Y IT employees experience career success by using the Kaleidoscope Career Model (KCM) as an interpretive lens.

Motivation for the study: Generation $\mathrm{Y}$ remains an understudied cohort with regard to perceptions of career success. Motivated by the potential value of constructing contexts, which promote career success among Gen Y, the KCM was used as a framework for exploring meanings associated with career success among this cohort.

Research approach/design and method: Semi-structured interviews were conducted with a purposive voluntary sample of 24 Gen Y IT employees. Data were analysed in a two-step process by, firstly, identifying elements associated with the central parameters of the KCM and, secondly, collating these to identify various sub-dimensions of each parameter, to identify associated meanings for subjective career success.

Main findings: The findings describe more richly the needs for authenticity (i.e. making a difference or work as an enabler of lifestyle), balance (within time and over time) and challenge (i.e. career success implies growth/turning problems into opportunities or goal attainment as signifier of success) as means to experience career success, specifically expanding the description of balance, where employees try to maintain a work-life balance not only within but also over time (synchronic vs. diachronic balance).

Practical/managerial implications: The findings have value for management and human resource practitioners with regard to the implementation of employment practices that will enhance perceptions of career success among Gen Y IT employees and the development of a supportive culture which underpin the latter.

Contribution/value-add: This study adds to our knowledge of Gen Y's perceptions of career success with particular emphasis on authenticity, balance and challenge. It furthermore contributes to career success literature by adding a career development lens to the latter.

Keywords: Generation Y; kaleidoscope career model; subjective career success; qualitative approach; work-life balance.

\section{Introduction}

\section{Orientation}

In present-day societies, where organisations are faced with global competition, companies can only remain competitive if they are able to attract and retain talented employees (Eversole, Venneberg, \& Crowder, 2012). Currently, many workplaces typically consist of four generations of employees - all with different opinions and expectations of their work environment ( $\mathrm{Ng}$, Schweitzer, \& Lyons, 2010). Generation Y (Gen Y) is fast becoming the prime-age workforce, with their numbers and roles increasing rapidly (Eversole et al., 2012). The literature suggests that Gen Y employees tend to be attracted to companies with forward-looking approaches to business as well as to those companies that will provide them with job variety ( $\mathrm{Ng}$ et al., 2010; Terjesen, Vinnicombe, \& Freeman, 2007), education and training opportunities to advance their careers (Luscombe, Lewis, \& Biggs, 2013) and a substantial salary (Terjesen et al., 2007). Also, Gen Y employees have an interest in developing their overall value in the labour market, instead of relying on a single organisation to provide them with long-term employment (Kultalahti \& Viitala, 2015). They are more likely to keep their career options open or to seek alternative employment, which can make it difficult to retain them in organisations (Suleman \& Nelson, 2011). According to Ng et al. (2010), Gen Y employees seem to hold 'values, 
attitudes, and expectations that are significantly different from those of the generations of workers that preceded them' ( $\mathrm{Ng}$ et al., 2010, p. 281). Not only do they seek rapid advancement, but they seem to have a need for a meaningful and satisfying life outside of work (Ng et al., 2010). As Gen Y employees consider quality of life a major priority, they have high expectations of their employers and of themselves (Suleman \& Nelson, 2011) and demand more time for activities outside of work (Kultalahti \& Viitala, 2015). In addition, Lyons and Kuron (2013) indicate in their review of generational theory research that employees are increasingly seeking personal fulfilment in their work, and leaders and employers who can satisfy their individualistic growth needs will have a competitive advantage in attracting and retaining talent. This amplifies the urgency of attracting and retaining employees from Gen Y.

While there has been a considerable increase in research on generations (especially Gen Y) over the past few years (see the overview of Lyons \& Kuron, 2013), there has been little discussion on Gen Ys' view of career success and their specific needs regarding contemporary careers. Mainstream publications on Gen Y either focus on Gen Y as the foci sample (Luscombe et al., 2013, Ng et al., 2010; Papavasileiou \& Lyons, 2015) or investigate the work values, career preferences, work expectations and characteristics of the different generations in comparative generational samples (Meriac, Woehr, \& Banister, 2010; Twenge, 2010). According to Hall, Lee, Kossek and Heras (2012), there is a gap in knowledge about how individuals adapt to changing demands to sustain both their careers and their personal lives psychologically and physically. Greenhaus and Kossek (2014) believe that the current career landscape, which is characterised by flatter and leaner organisational structures that provide fewer opportunities for hierarchical advancement, influences the achievement of career success. Consequently, employees have to develop their own idiosyncratic views of what constitutes a successful career. This resonates strongly with the newer conceptualisations of subjective career success, which implies a subjective judgement or evaluation by the individual (Abele \& Spurk, 2009; Dries, Pepermans, \& De Kerpel, 2008; Ng, Eby, Sorensen, \& Feldman, 2005).

Heslin (2005) argues that despite the extensive literature available and focal change in objective towards more subjective facets, career success has been defined too narrowly in the past. He adds that scholars should focus on a broader range of criteria to explore subjective career success. According to the self-determination theory (SDT), the social context in which people live and work should satisfy their basic psychological needs. In such a case, the context should provide the appropriate developmental lattice for improved human achievement and enhanced well-being, and by implication, people's perception of success (Ryan \& Deci, 2000). Thus, it can be argued that to achieve subjective career success, people's career-related needs should be met.

One of the more contemporary developmental models used to investigate contemporary careers is the Kaleidoscope Career
Model (KCM). This model was developed originally to explain how women shift their career patterns by rotating different aspects of their lives to arrange roles and relationships in nontraditional ways, in response to their unique needs (Mainiero \& Sullivan, 2005; Sullivan \& Mainiero, 2008). In the process, three central parameters of career decision-making emerged, namely, the need for authenticity, balance and challenge. Authenticity represents individuals' need to be true to themselves and their values; balance refers to individuals' wish to enjoy quality experiences in both work and family domains; challenge refers to an individual's need to participate in intrinsically motivating work (Sullivan \& Mainiero, 2008).

According to this model, employees evaluate the choices and options available through the lens of the kaleidoscope to determine the best fit among their multiple relationships, work constraints and opportunities. In light of the discussion above, the KCM's focus on career-related needs provides a valuable theoretical lens to understand how employees construct subjective interpretations of success in response to unfolding career experiences (Heslin, 2005) as well as the extent to which these experiences allow their career needs to be met. As far as the researchers could determine, no previous research has been conducted to date on career success using the framework of the KCM.

\section{Research purpose and objectives and motivation for the study}

This study was motivated by a gap in the generational and career literature regarding the conceptualisation of subjective career success for Gen Y employees in contemporary careers. The goal was to investigate how Gen Y employees experience subjective career success using the Kaleidoscope Model as an interpretive lens. More specifically, the study set out to identify what subjective career success means to them, with regard to their needs for authenticity, challenge and balance. This study was based on the following research question: How do Gen Y employees conceptualise subjective career success within the framework of the KCM?

\section{Literature review}

\section{Generation Y}

While in some quarters there is some scepticism about the concept of generations as a meaningful focus of study, it has a sound basis in both psychology (Laufer \& Bengston, 1974; Pilcher, 1994) and sociology (Parry \& Urwin, 2011). The value of the concept lies in its ability to capture diversity across time frames. Turner (1998) defined a generation as:

... a cohort of person's passing through time who come to share a common habitus and lifestyle....[and] has a strategic temporal location to a set of resources and exclusionary practices of social closure. (Parry \& Urwin, 2011, p. 81)

Viewing a generation as a cohort allows one to identify relatively homogenous categories of people, who are likely to have meaningful commonalities based on the dominant societal and work contexts in which they function (Ryder, 1965). Understanding the differences between these 
cohorts can have significant benefits for managers in adapting organisational practices to best suit a generational cohort.

\section{Subjective career success}

The concept of career success has been well defined in the literature over the past few decades. Initially, career success explanations described how an employee progresses in the hierarchy of an organisation; therefore, individuals receiving higher wages are generally regarded as being successful in their careers (Judge, Cable, Boudreau, \& Bretz, 1995). However, recent conceptualisations moved towards distinguishing between objective and subjective career success. Objective career success is judged by external people based on visible criteria such as job level, income, status, salary and occupation (Ng et al., 2005). Subjective career success is based on the internal components that involve individual employees' personal inner interpretations, perspectives and evaluations of their career achievements (Arthur, Khapova, \& Wilderom, 2005). Thus, subjective career success can be understood as a subjective construct representing individual employees' interpretation of success. According to Gunz and Heslin (2005), it is possible to develop general patterns of understanding by identifying themes that are important to individuals who share social contexts, as may be the case for Gen Y employees. Some recent studies of subjective career success have been conducted in specific contexts or on particular groups. These include managers (Grimland, Vigoda-Gadot, \& Baruch, 2011; Visagie \& Koekemoer, 2014), academics (Beigi, Shirmohammadi, \& Arthur, 2018) and blue-collar workers (Koekemoer, Fourie, \& Jorgenson, 2018).

\section{Motivation for the use of the Kaleidoscope Career Model}

Although the KCM was originally developed to explain the career development of women, the initial developers of the model, Sullivan and Mainiero (2008), argue the applicability of this model in the contemporary career landscape well. They postulate that the KCM is one of the few contemporary models that is grounded in the literature and can be used in contemporary career research. This is especially given the rapid environmental changes, including increased globalisation, an increasingly diverse workforce, technological advances and the growth in the conceptualisation of nontraditional careers. The KCM offers a means for studying processes within non-traditional careers or non-traditional career concepts such as subjective career success. In previous research on the $\mathrm{KCM}$, the focus was primarily on gender differences; however, Sullivan and Baruch (2009) have noted generational differences in the need for authenticity, balance and challenge. They have shown that members of Generation $X$ have higher needs for authenticity and balance than the so-called baby boomers, but their study did not include employees from Gen Y. Various studies have already suggested that generations might use kaleidoscope thinking when making career decision or when shifting career patterns (Lyons, Schweiszer, Ng, \& Kuron, 2012; Sullivan, Forret, Carraher, \& Mainiero, 2009), thus making the use of the KCM principles relevant to studies focusing on generations (in this case, the study of Gen Y employees). Motivation for linking subjective career success with the
Kaleidoscope Career Model

When considering the parameters of the KCM and subjective career success, possible associations can be made. For instance, the challenge parameter of the KCM (which is an individual's need for stimulating work and career advancement) is similar to views of subjective career success (Visagie \& Koekemoer, 2014). Recently, Mayrhofer et al. (2016) specifically explored the meanings of career success in their 5C Project (CrossCultural Collaboration on Contemporary Careers) and divided career success into four overarching themes: material concerns (i.e. financial security and financial achievement), learning (i.e. learning and development), social relations (i.e. work-life balance, positive impact and positive relationships) and pursuing one's own project (i.e. entrepreneurship). When considering these contemporary notions of career success, the social relations theme (i.e. positive impact and work-life balance) resonates strongly with the authenticity and balance parameters of the KCM. Therefore, it stands to reason that career success might be more closely viewed through the lens of the KCM as Ballout (2008, p. 440) points out: 'Individuals view their career success as a function of their own internal standards and perceptions of satisfaction and success in social networks of relationships with others'. Furthermore, the KCM posits that needs for authenticity, balance and challenge over the course of a career will be present, but may vary in intensity over an individual's life span (Mainiero \& Gibson, 2017). Thus:

... over the course of the life span, as a person searches for the best fit that matches the character and context of his or her life, the kaleidoscope's parameters shift in response. (Sullivan et al., 2009, p. 291)

This is similar to the view that the concept of subjective career success is based on the understanding of a career as the 'evolving sequence of work experience over time' (Arthur, Hall, \& Lawrence, 1989). This is also in line with Visagie and Koekemoer (2014), who posit that a subjective career is seen as a journey of progression, where subjective career success is an ongoing process of progress towards achieving goals and a life-long journey.

Given the above-mentioned discussion, the findings of the study are expected to provide a better understanding of subjective career success, which could be useful to individuals, employers, educators and policymakers as they help to situate the views of Gen $Y$ on modern careers within a KCM perspective.

\section{Research design Research approach and strategy}

The research was conducted from an interpretive perspective, which implies an in-depth understanding of a phenomenon in context, in this instance, subjective career success (Crotty, 1998). Using the dimensions of the KCM (authenticity, balance and challenge) as a lens, the aim was to explore the meanings Gen Y IT employees attach to subjective career success (Babbie \& Mouton, 2001) by means of a qualitative survey (Fink, 2003; Jansen, 2010). 


\section{Research method}

\section{Research setting}

A purposive voluntary sample of Gen Y employees was drawn from the South African division of a global IT organisation, "TechCo'. The interview data and company website both suggest a challenging environment characterised by constant innovation and cutting-edge technological developments and consequently a strong focus on learning and development. TechCo requires local employees to work with people from other countries and cultures as well as across time zones. This implies long working hours, tight deadlines and employees being available after hours, elements that may influence worklife balance. The company is, however, considered familyfriendly and employees have the option of working flexible hours, as highlighted in both interview data and company documentation. Because of the nature of the environment and the large number of Gen Y's who comprise the employee-base, TechCo provided an ideal context to explore the basic tenets of the KCM model in relation to the subjective career success of Gen Y's.

\section{Entrée and establishing researcher roles}

The data were gathered by a Gen Y fieldworker employed by the company, and analysed by the current authors. The fieldworker was trained in interviewing skills by one of the current authors. Having a familiar fieldworker from the same cohort meant that participants were able to easily relate to her in sharing their experiences. Consent was obtained from the target organisation to collect the data as well as from individual research participants who volunteered to be part of the study. The anonymity and confidentiality of participants were ensured through the allocation of participant numbers to the interviewees (Babbie \& Mouton, 2001).

\section{Research participants and sampling methods}

Based on the generation categorisation of Parry and Urwin (2011), a purposive voluntary sample of 24 employees, born between 1982 and 2002, was interviewed. The study sample included eight female participants (33\%). The majority of participants were born between 1982 and 1987 (with a mean age of 31) and 58\% of the participants had eight or more years of work experience. The majority of the sample (96\%) had a tertiary qualification. Twelve employees were in possession of higher education diplomas, while five others had postgraduate qualifications. Only one participant had a grade 12 or lower qualification. Regarding the relationship status of participants, 11 were married, eight were engaged or in a relationship, four were single and one was divorced. Five participants had children at the time of the study. Employees were drawn from all areas of the organisation, including software development and testing, business analysis, server support and various management roles, and were on job level 1 or 2 .

1.'TechCo' is a pseudonym representing Technology Company

\section{Data collection methods}

A total of $24^{2}$ face-to-face semi-structured interviews were conducted that enabled data saturation to be attained (Onwuegbuzie \& Leech, 2007). Guided by the interpretivist approach, which emphasises individual constructions of meaning, a few broad questions were constructed to elicit the meanings Gen Ys attach to the concept of career success. Examples were the following: 'Tell me about your understanding or view of career success'; 'What are the things that are important to you in your career?' and 'What do you need in order to view yourself as being successful in your career?' In addition, the interviewer also used probing questions and other communication techniques such as paraphrasing, reflection, clarifying and summarising to elicit more information from the participants.

\section{Data recording}

All interviews were tape recorded and transcribed verbatim. To ensure confidentiality, participants were assigned numbers that form the basis of the reporting here.

\section{Strategies employed to ensure data quality and integrity}

Guided by strategies suggested by Miles and Huberman (1994), the following steps were taken to ensure the quality of the data. To ensure dependability, data were generated by one interviewer and the analysis guided by clear analytical constructs, as described in the $\mathrm{KCM}$ theory and its operationalisation (Sullivan et al., 2009). To enhance authenticity and credibility, the researchers sought to provide context-rich and meaningful descriptions of the setting and findings (space permitting). In addition to data from interviews, the company website was studied to form a sense of the 'public face' of the company providing more details regarding the organisational context. Transferability of the findings was ensured by providing a detailed description of the setting and sample.

\section{Data analysis}

Our first step was to conceptualise the parameters of the KCM, namely, authenticity, balance and challenge, as these have been outlined in the literature so as to recognise similar or related elements in the Gen Y cohort. To do so, we conducted a careful reading of KCM research paying particular attention to the descriptions of the parameters as operationalised in the authenticity, balance and challenge scales, as described by Sullivan et al. (2009). Examples of these include 'If I could follow my dream right now, I would' (authenticity); 'I constantly arrange my work around my family needs' (balance) and 'I continually look for new challenges in everything I do' (challenge). The second step was to analyse the interview data to identify and code elements related to authenticity, balance and challenge (Braun \& Clarke, 2006). Extracts of the data relating to each of these parameters were then collated and subjected to second-order coding to identify

2.A total of 26 interviews were conducted, of which 24 formed the basis of the final analysis. 
the sub-themes within each parameter, as they pertain to the Gen Y sample. The final description of each parameter rested on the researchers' interpretations and unique constructions of the data set (Crotty, 1998).

\section{Reporting style}

The authors are reporting this study as a confessional tale so as to do justice to the participants and their multiple voices (Sparkes, 2002).

\section{Ethical consideration}

This article was part of a master's study for which ethical clearance was obtained from the Department of Human resource management (HRM) at the institution.

\section{Results}

In making sense of the findings presented below, the reader is advised to bear in mind the description of the organisational context as described as part of the research setting (Miles \& Huberman, 1994).

The results are presented, as they were analysed, within the dimensions of the KCM, namely, authenticity, balance and challenge. In Table 1, we present a summary of the dimensions of the KCM and the sub-themes extracted from the data that form part of each. It also includes $\mathrm{s}$ description of the implication of each sub-theme for subjective career success based on the data.

Each of these will now be discussed in more detail.

\section{Sub-themes related to authenticity}

Because the Gen Ys in the sample spend long hours at work, they want to enjoy what they are doing and ensure it is meaningful. Participants emphasised that career success should be defined by personal choices rather than others' expectations (Ballout, 2008).

TABLE 1: Sub-themes extracted from the data in relation to the authenticity, balance, challenge (ABC) parameters.

\begin{tabular}{|c|c|c|}
\hline KCM parameter & $\begin{array}{l}\text { Sub-themes of parameter } \\
\text { as extracted from the data }\end{array}$ & Key idea/concept \\
\hline \multirow[t]{2}{*}{ Authenticity } & Making a difference & $\begin{array}{l}\text { Subjective career success means } \\
\text { making a difference }\end{array}$ \\
\hline & $\begin{array}{l}\text { Work as an enabler for } \\
\text { lifestyle }\end{array}$ & $\begin{array}{l}\text { Subjective career success means } \\
\text { my work is able to fund personal } \\
\text { dreams and hobbies }\end{array}$ \\
\hline \multirow[t]{2}{*}{ Balance } & $\begin{array}{l}\text { Balance within time } \\
\text { (synchronic) }\end{array}$ & $\begin{array}{l}\text { Subjective career success means } \\
\text { balancing physical, emotional, } \\
\text { relational, task-related demands }\end{array}$ \\
\hline & $\begin{array}{l}\text { Balance across time } \\
\text { (diachronic) }\end{array}$ & $\begin{array}{l}\text { Subjective career success implies } \\
\text { balance considered across an } \\
\text { extended period of time }\end{array}$ \\
\hline \multirow[t]{3}{*}{ Challenge } & Success implies growth & $\begin{array}{l}\text { Subjective career success means } \\
\text { constant growth }\end{array}$ \\
\hline & $\begin{array}{l}\text { Turning problems into } \\
\text { opportunities }\end{array}$ & $\begin{array}{l}\text { Subjective career success means } \\
\text { being able to turn problems into } \\
\text { opportunities }\end{array}$ \\
\hline & $\begin{array}{l}\text { Goal attainment as } \\
\text { signifier of success }\end{array}$ & $\begin{array}{l}\text { Subjective career success is } \\
\text { achieved through a continuous } \\
\text { process of goal setting }\end{array}$ \\
\hline
\end{tabular}

KCM, Kaleidoscope Career Model.
You need to judge yourself and your career success on what you have set for yourself, not based on what your friend is achieving, or what your family or other people expect you to achieve (P3, female, software testing).

Participants linked authenticity to 'making a difference' and 'work as an enabler for lifestyle'. The first sub-theme is similar to the dimensions of authenticity that relate to purpose and having an impact, as described in Sullivan et al. (2009). The second sub-theme describes non-work-related dreams and goals, which provide meaning and a sense of purpose; however, because of financial constraints, these cannot be pursued full time. Working, thus, enables from financial perspective, the fulfilment of goals and dreams, which provide a sense of authenticity. Both sub-themes are discussed subsequently.

\section{Making a difference}

The Gen Ys from the sample defined career success primarily in terms of 'making a difference' (P6, P10, P13, P21, P25 ) or 'adding value' (P2) to the greater good. This meant taking the basic job requirements and making a unique contribution in ways that improved its value:

'... anyone that fits the job profile would have come in and done just the bare minimum, I'm looking to go and explore that role, see what value I can bring in personally.' (P24, male, project manager)

At times, making a difference was referred to in task-related terms, for example, developing a piece of new software. However, most often it implied relational impact, envisaged in two inter-related ways. Firstly, the role of mentoring and coaching to help others becomes more proficient, achieve their work-related goals and thus be more successful in their work:

'I would be in a position that I could mentor other people and help them to become more proficient in their job and more successful.' (P11, male, database administrator)

The second role was being a role model to others, enabling them to learn from their own journey and provide opportunities for growth:

'I want to make a difference in a lot of lives of people who work here, grow them, give them job security, give them options ... get people to learn from my journey, my mistakes.' (P25, male, IT management)

One of the participants suggested that making a difference could be achieved on a day-to-day basis solving immediate problems, but should also be measured in terms of having worked towards a strategic goal - described as:

$$
\text { '... taking a chip off a big block.' (P10, male, management) }
$$

Several participants also highlighted the perceived importance of organisational rank or level in making a difference:

'I find a lot of self-value if I can see other people grow - and being in executive management... you can influence a lot of the bigger organisational wide decisions to see that change comes through at several levels, not just one.' (P23, male, management) 3.As indicated a total of 26 interviews were conducted, of which 24 formed the basis of the final analysis. 
This suggests a link between the need for authenticity and more objective measures of success, such as moving up the organisational hierarchy. This has implications for our views of subjective and objective as distinct measures, and implies a more nuanced view of success in which certain practices or outcomes can provide both objective and subjective consequences for success.

Making a difference meant changing circumstances and improving people lives, but this was dependent on being given the freedom to do so and was enabled or constrained by organisational culture. Referring to this issue, participant 21 commented that where the company culture is dominated by red tape, a Gen Y would be constrained with:

'... no freedom to sort of stretch your wings and be an individual and make a difference.' (P21, male, business analyst)

\section{Work as an enabler for lifestyle}

This category represents the perspective of a smaller group of Gen Ys within our sample. For these participants, success was defined in financial terms, but not necessarily as mere accumulation of wealth, rather as a means to support their lifestyle and its associated hobbies and activities. Participant 7 was an avid sportsman and viewed work as one element of his life only, and an enabler for other, more exciting aspects:

'I do feel that a job should be an enabler, I don't think it should be central to, to what you do in your life. It's looking back [...] Ahh no, I have been a project manager, that is kind of what I have done; no, I don't like that. I would rather tell stories of conquests and adventures.' (P7, male, project management)

When asked about career success, participant 21 immediately answered - money but quickly went on to explain that the reason for this was that it enabled him to do the things he loved. He explained that coming from a background where his parents lived from 'cheque to cheque' meant there was little stability and he longed for financial wealth to enable him to do the things he loved:

'Okay, so I mean obviously if I personally had a choice between what I am doing now, if I had a, if I had unlimited financial resources, I would probably be in another skillset, I would probably be off cooking or sailing or something like that so, um I guess part of my movement and my aim at studying and working is to increase my sort of financial wealth, in such a way so that I can actually do some of the other things that I love.' (P21, male, business analyst)

\section{Sub-themes related to balance}

When considering the balance parameter, the Gen Ys in the sample gave various perspectives of ways in which balance contributes to their view of career success. Some participants suggested they should be able to separate work and life, thus achieving a comfortable balance. Others were satisfied with blurred edges in which work and personal life co-existed comfortably, or less comfortably. Overall, the research identified two distinct ways in which participants attempted to achieve balance: 'balance within time' or synchronic balance, and 'balance across time' or diachronic balance. Synchronic, in this regard, entails balancing work and personal commitments within a given shorter time frame. Conversely, diachronic refers to a pattern of balancing work and personal life over an extended period during which varying amounts of time and energy are given to each domain, depending on the need at a given moment.

Given the age range of the Gen Y cohort, most of the sample were in the process of establishing themselves in their line of work and were not yet financially secure. For this reason, many of them were prepared to spend very long hours at work to establish themselves in their careers and develop a basis for financial security. In many instances, this seemed a deliberate choice with the understanding that once they were more established in their careers, they would have earned the right to more personal and family time.

The mentioned balancing act differed among the participants and was influenced by the nature of their specific job and its flexibility as well as their unique personal circumstances. Other factors were their financial situation, spousal and family support, personal drive and ambition, and personal preferences. Several participants pointed out the importance of company culture and its emphasis on flexibility in the quest for balance:

'TechCo has that culture, that flexibility culture ... we have a flexible environment where you can do other things, other than work but make sure you still have your work, that you get your work done, so personally I can still train, I can still run errands during working hours and make up the time.' (P13, male, software testing)

While several participants mentioned the flexibility, one at least suggested this was dependent on a person's direct line manager and there seemed to be some differentiation here.

\section{Balance within time (synchronic)}

Participants referred to various ways in which they could balance their commitments within time. Firstly, several highlighted balancing their work and personal lives in physical terms, and suggested they would feel successful when able to live out a '... work-hard, play-hard philosophy' (P9). Participants stressed the value of having a healthy lifestyle to work more productively and perform at a higher level. Training during lunch hours was mentioned specifically, as the company has gym facilities. Participant 13 summed this up:

'... if you are not healthy, I don't think that you will perform well, so if I was not allowed to train during the day, I think I would be a frustrated man ... if I go and run in lunch time I come back a better person, so I can focus and work around solutions.' (P13, male, software testing)

This solution focus is central to the challenge parameter, and further reinforces the possible relationships among the three parameters. This also provides a more personal view of balance - one in which employees are able to balance their own personal (e.g. training) and work needs. This is a 
variation on the way balance is conceptualised in Sullivan et al. (2009), who focus clearly on the work-family balance.

The second area contributing to participants' perception of success concerned emotional spillover from home to work, and vice versa, where they indicated how extremely difficult it was to separate these two domains from an emotional perspective:

'... I said career success and personal life are two separate things but when you are - I think - happy in your career, your career plays such a huge role in your life, I think it does translate into your personal life.' (P6, female, talent branding)

While this reflects a positive spillover, participants cited several examples of emotional pressure that influenced their mood and ability to cope, thus affecting their functionality in other domains such as their work or family. Examples are the following: anxiety about the safety of a spouse, worrying about relatives who are ill, their job satisfaction, financial pressures and the responsibility to provide for their family.

Thirdly, relationships at home and at work were important to the participants, but made separating their work and personal life particularly challenging:

'But I think personal life, at least the way I do it, is just as much here at work as at home ... I say, "Ahh guys, I'm going overseas and my car is going to cost me nine grand. I'm devastated" ... I know we are all professional, but in a way you get a little work family.' (P21, male, business analyst)

Thus, work relationships provide a valuable source of emotional support and function to simulate family relationships. Relationships at home were also considered a means of vital support. In this regard, many participants referred to the value of spousal support both emotionally (being a 'cheerleader') and practically ('pulling their weight' in household responsibilities) as critical to career success.

Finally, the area of the task was assumed to be the easiest level at which work-life balance could be achieved. Nevertheless, given the nature of the work environment, the ideal of separating the two domains was not always possible as suggested by participant 20:

'I have this thing where, six o' clock I walk out the door, I can detach, uhm, I can go home and not think about work, unless it's like something really important that needs to be done, uhm, or someone calls me and says you know what, we have this issue, can you have a look at it?' (P20, male, software testing)

Matters that were attended to at home were found to be emails, doing standby work from home, work-related studies and spending time focusing on solutions for which there were no time at work. Some participants were unable to separate the two domains as they worked on standby:

'... okay, so for me work impacts my social life quite badly uhm... I work support 24/7 which means I get called any day any time, uhm, I mean a good example is Easter, Easter Friday I didn't do much, I worked from eight on Friday morning and I finished off at six on Saturday morning.' (P10, male, management)
Participants justified these intrusions into their home domain by viewing it as temporary. Thus, they were willing to make a reasonable sacrifice for what they perceived as rewards they could reap at a later stage. The notion of deferred benefits relates to balance over time, which is expounded below.

\section{Balance over time (diachronic)}

Balance over time means conceptualising work-life balance as a give-and-take relationship between the employees and their work, over an extended period of time, linked to various life stages. At times the Gen Y employees would be able to 'give' more, and other times they would need to 'take' more:

'... like when you are single you know you have more time on your hands to give overtime, but later on, you know when you have kids and you are married and you have a family, uhm, you have less time - you know, some weeks might be less than nine to five.' (P19, male, software testing)

The age parameters associated with Gen Ys imply that they are in the early establishment phase (25-44 years) of their career (Super, 1980). Therefore, they are still developing work experience, building skills and beginning to stabilise their careers. Several young, single participants were comfortable about thinking ahead with the belief that they were establishing themselves and needed the knowledge, skills and experience as investment in their future:

'Right now it's not balanced, it's more of a work life, I work a lot, I work long hours ... so for me it's over the next three years I want to be in that management position where I can align everything and then obviously look at starting a family.' (P10, male, management)

Thus, this cohort of Gen Ys were content to make the sacrifices and invest in the extended hours as part of their development. They believed that when they had reached a particular level of seniority (broadly referred to as 'management') and maturity, they would have greater flexibility and the capacity to say No. Based on this sub-theme, it seems that balance over the short term was, thus, sacrificed on behalf of the longer term. Nevertheless, we had questions regarding how viable this belief actually was. The reason was that a number of our participants had already attained management positions, but were still struggling to balance their work and personal lives. Evidently, this area warrants further exploration.

\section{Sub-themes related to challenge}

Given the context in which the sample of Gen Y functions, 'challenge' was expected and confirmed to be a significant driver in employees' views of career success. Participants mentioned an element of challenge as a central feature for such success:

'I wanna say that it is human nature to be challenged; uhm, people do tend to stagnate $[. .$.$] so that challenge I don't know keeps the$ mind fresh, keeps the spirit fresh.' (P7, male, project management)

'A lack of challenge was viewed as 'the complete opposite of what we describe as career success.' (P19, male, software testing)

Central to the idea of challenge in this group of Gen Ys was the value of growth and development as contributing to 
career success. This notion is consistent with the literature on Gen Ys, though not included explicitly in the conceptualisation of 'challenge' by Sullivan et al. (2009).

\section{Success implies growth}

Participants posited a close relationship between career success and growth with participant 3, suggesting that success was authentic only if accompanied by growth. The reason was that they did not view success as a final static destination, rather a journey involving successive phases of growth:

'One can never say that there is complete success ... there is always room for growth or always new things that you can learn.' (P3, female, software testing)

'I could feel proficient in something today and in a year's time, not be proficient anymore because they have added a whole lot of things to it. So that is also what drives me to learn.' (P11, male, database administrator)

Because the context in which they function is constantly evolving, they too are required to develop, staying abreast of the developments in their field. The dynamic, fast-paced technological environment requires of Gen Ys to constantly learn and grow, thus providing a constant source of challenge. The emphasis on growth may attributable to the degree of change experienced in this particular industry but given the nature of the globalised world is likely to apply in other contexts as well.

\section{Turning problems into opportunities}

Coupled with the emphasis on growth was the ability to turn work problems into opportunities for development consistent with findings by Sullivan et al. (2009). Participant 25 shared an experience - which he suggested was common in the company - of Gen Ys being promoted to managerial level at an extremely early age because of their technical competence. Such a promotion has two unintended consequences.

Firstly, the Gen Ys were no longer able to rely on the sense of achievement from being technically strong, which led to ambivalence about their career choices. Secondly, they found themselves in a position of being inexperienced in managerial competence and ill-equipped to hold their own against older and more experienced colleagues:

\footnotetext{
'You go in and you get totally steamrolled or out-snookered or out debated. I always take it quite personally, but to actually go and say, 'Well hang on a second, what have you learnt on that?' Because you might get beaten thirty times, but you will win that thirty first and the thirty second, so you use that in going forward.' (P25, male, IT management)
}

The importance of the above-mentioned insight into challenge for Gen Ys is two-fold. Firstly, it demonstrates participants' ability to make sense of these difficult moments, by choosing to focus on potential benefits and demonstrating tenacity in the face of adversity. Secondly, even though participants were initially outperformed by their more senior colleagues, they were able to learn from these situations and develop their own skills, applying what they had learnt to their own advantage.

\section{Goal attainment as signifier of success}

Closely related to growth, career success was also viewed as a process of setting and achieving goals:

'Career success, in my understanding is achieving your goals.' (P20, male, software testing)

However, this must not be considered as a once-off event, but rather a continual cycle of goal setting and achievement. Growth is attained by setting these 'realistic milestones' as mentioned by Participant 18, (a female project management), achieving these and then setting new, more challenging goals, allowing one to grow and develop further.

This meant that participants viewed career success not so much as a destination but rather a continual journey of milestones that provided feedback on progress and reassured the participants that they were continually successful:

'I felt like I have already reached my goal, but now I need to set higher goals and just raise that ladder ... there is always room for growth and there is always ladders to raise and there is always goals to set.' (P26, female, project management)

'I would say there is never an end goal of career success; there is always room to grow to the next level, get better at another area.' (P8, male, software development)

Inherent in the process of goal setting is the aim of career advancement, and part of the means by which this is achieved. The Gen Ys in the sample believed that career success would mean advancing through the hierarchy in the organisation; several mentioned moving to the next level, drawing on the metaphor of the ladder. The emphasis was, however, on advancement as means to grow and develop, and goal setting as the way to achieve this result. Once again, objective and subjective means of career success are interlinked, with subjective means of success, namely, growth and development, dependent on objective means, such advancing through the organisational hierarchy.

\section{Discussion \\ Outline of the results}

The present study used the KCM as a framework to extract the meanings of subjective career success. The findings showed how fulfilling the needs for authenticity, balance and challenge may lead to feelings of career success. Thus, by providing an in-depth exploration of Gen Y's perceptions of subjective career success, the study contributes to a contextual understanding of this concept within an IT environment.

Firstly, the sample expressed the importance of making a difference, which is similar to a dimension of authenticity in the KCM scale by Sullivan et al. (2009). According to the participants, making a difference has both a task and relational dimension, focusing on being a role model as well 
as mentoring and coaching those around them. It could be argued that this may be attributed to the strong developmental focus of the company, often required within an IT environment. However, generational literature also highlights the need of Gen Ys for meaningful work through which they can make a difference (Blain, 2008). Thus, making a difference is a notion of authenticity that could be explored further.

Although Sullivan et al. (2009) focus on living a dream, the participants described work as an enabler for other equally important facets of their personal lives such as participation in sport. This is consistent with the literature on Gen $Y$ that highlights this cohort's need and time for meaningful and satisfying activities outside of work (Kultalahti \& Viitala, 2015; Ng et al., 2010). The participants clearly related the mentioned needs to their perception of career success.

Secondly, balance, as conceptualised by Sullivan et al. (2009), differed considerably from the way the sample sought ways to juggle both work and personal considerations. In the first instance, balance was conceptualised more broadly to encompass work and personal life. For the sample, the nonwork domain did not only include family, but also reflected the various aspects of their personal lives. Several participants had significant personal projects outside of work, which were not family-related (e.g. exercise, sport or hobbies such as blogging and travelling), but which drove them to maintain a balance. This is in line with more contemporary workfamily research (Keeney, Boyd, Sinha, Westring, \& Ryan, 2013). Although the concept of work-life balance (also known as work-family balance) is a popular concept in work-family literature and known as a prominent facet that employees seek in the new career area (Epstein \& Hershatter, 2014; Ng et al., 2010), Wayne, Butts, Casper and Allen (2017) argue the need for scholars to develop a more comprehensive theory of balance and build a cohesive body of research, conceptual elaboration and empirical examination of the existing approaches to work-family balance. In this regard, the current study adds to this conceptual understanding of balance within the KCM framework and the different time frames according to which balance is conceptualised. In the work-family literature, the seminal definition provided by Greenhaus and Allen (2011) defines work-family balance as 'the overall appraisal of the extent to which individuals' effectiveness and satisfaction in work and family roles are consistent with their life values at a given point in time'. In this explanation, work-family balance is viewed or described as a synchronic balance, where individuals attempt to obtain balance in their current situation or time. As mentioned previously, participants in this sample explained that they seek to achieve balance both within a given timeframe and over longer periods of time. This led to an explanation of how balance is viewed in the current time frame, as well as a strong emphasis on the future and how balance should be reflected over time to attain feelings of career success. These elements are new contributions in the work-family and KCM literature.
Thirdly, the sample furthermore described how elements of challenge led to feelings of career success. Given the qualitative nature of the present study, the researchers expanded on descriptions of challenge by Sullivan et al. (2009). Participants in the present study emphasised the need for growth and explained how work problems were turned into opportunities for development, which ultimately led to feelings of career success. According to the participants, success is never 'achieved' in a final form because the opportunity for growth is continuous. Closely related to growth, and a mechanism to achieve it, is goal setting. As was found, the latter is also viewed as cyclical, which reinforces the nature of 'milestones of success' (the researchers' phrasing) rather than a fixed point or destination. This is in line with previous research, which suggests that career success can be viewed as a life-long journey and an ongoing process of progression (Visagie \& Koekemoer, 2014).

In light of the discussion above, it was suggested that the KCM provides a suitable lens through which to view the career success of Gen Ys in an IT environment. The initial development of this model to meet the flexibility requirements of women resonates well with the need for fluidity described by the Gen Y sample taken from an IT environment.

\section{Limitations and recommendations}

Firstly, the sample included primarily highly educated people working in an IT environment. In this context, certain limitations must be factored in. Firstly, conceptualisation of career success would only be transferable to IT and similar environments, which are characterised by extended working hours, fast-paced and demanding work schedules, a culture of flexibility and a work-family awareness. Although these findings may not represent the views of career success for all Gen Ys, they provide a starting point to explore career success among this generation group by applying the KCM.

Secondly, participants' views were gathered at a single point in time, and apart from the company website, the research relied heavily on interview data, which provided limited opportunity to verify these perspectives (Brown, 2010).

\section{Practical implications}

Based on the findings, the parameters of the KCM provide a useful framework that can be applied to attract and retain Gen Y employees. Regarding authenticity, participants emphasised making a difference in either task-related or relational terms. The postulation is that should Gen Ys be given the opportunity to lead through example (e.g. through formal performance agreements), they may experience feelings of career success. Specific opportunities could include mentoring and coaching, hierarchical reporting lines or informal career discussions among peers. However, such opportunities should give employees a genuine chance to 'make a difference', otherwise they will miss the challenge associated with such an opportunity. For instance, opportunities to solve problems, by setting either challenging 
short-term goals or strategic goals, may make them feel that they add value to the organisation and that this personal contribution is recognised as invaluable. Yet, as suggested by the data, such a management style depends on the organisational culture. Therefore, organisations should become more cognisant of formal policies and procedures that may inhibit Gen Ys' autonomy and initiatives.

The research findings indicate that organisations operating within an IT setting could retain their Gen Ys better if the latter perceive their work environment as supporting their preferred lifestyle and if they experience a measure of work-life balance (Ryan \& Deci, 2000). It is suggested that this aspect should be monitored more closely to ensure consistent use across the organisation. Furthermore, from a career development point of view, these findings could assist counsellors when counselling employees from this cohort who may struggle with issues of balance, as the study has provided greater understanding of balance within time frames as well as across time frames. Various types of balance within a time frame are also highlighted that may guide more focussed interventions in this regard. During counselling sessions, these aspects can be explored more. Organisations (by implication managers) should also take note of these findings, as they should be cognisant of the way in which employees attempt to balance their work and family demands. They could support employees by rethinking the demands they make on their employees, as they sometimes are willing to give more to their careers, and at other times their family is prioritised. A further inference from the findings is the importance of setting goals that describe the career, tasks or strategies for Gen Ys. The reason is that goal setting seems to be linked closely to their growth and development as well as their career success. In the whole, the present study adds valuable insights into authenticity, balance and challenge as parameters of the KCM, which can be applied in a strategy to retain Gen Y employees in contemporary IT careers.

It is recommended that similar studies be conducted in Gen Y cohorts in other contexts quite different from the current one to see whether similar perspectives exist, thus providing a comprehensive understanding of this very important cohort.

\section{Acknowledgements}

This research is based on work supported by the National Research Foundation (NRF) under the reference number TTK14051567368. Thank you to the National Research Foundation provided funding for this research. The authors also acknowledge that opinions, findings and conclusions or recommendations expressed in this publication generated by the NRF supported research is that of the authors and that the NRF accepts no liability whatsoever in this regard. They would also like to acknowledge and thank Emari Erxleben for conducting the interviews.

\section{Competing interests}

The authors declare that they have no financial or personal relationships that may have inappropriately influenced them in writing this article. The views and opinions expressed in this article are those of the authors and are not necessarily attributed to the National Research Foundation.

\section{Authors' contributions}

E.K. was responsible for the main conceptualisation of the study, writing of the article and analysis of the data. A.C. focussed on analysis of the data and writing of results and methodology section.

\section{References}

Abele, A. E., \& Spurk, D. (2009). The longitudinal impact of self-efficacy and career goals on objective and subjective career success. Journal of Vocational Behavior, 74(1), 53-62. https://doi.org/10.1016/j.jvb.2008.10.005

Arthur, M. B., Hall, D. T., \& Lawrence, B. S. (1989). Handbook of career theory (p. 68), Cambridge: Cambridge University Press.

Arthur, M. B., Khapova, S. N., \& Wilderom, C. P. M. (2005). Career success in a boundaryless career world. Journal of Organizational Behaviour, 26(2), 177-202. https://doi.org/10.1002/job.290

Babbie, E., \& Mouton, J. (2001). The practice of social research. Cape Town: Oxford University Press.

Ballout, H. I. (2008). Work-family conflict and career success: The effects of domainspecific determinants. Journal of Management Development, 27(5), 437-466. https://doi.org/10.1108/02621710810871781

Beigi, M., Shirmohammadi, M., \& Arthur, M. (2018). Intelligent career success: The case of distinguished academics. Journal of Vocational Behaviour, 107, 261-275. https://doi.org/10.1016/j.jvb.2018.05.007

Blain, A. (2008). The millennial tidal wave: Five elements that will change the workplace of tomorrow. Journal of the Quality Assurance Institute, 22(2), 11-13.

Braun, V., \& Clarke, V. (2006). Using thematic analysis in psychology. Qualitative Research in Psychology, 3(2), 77-101. https://doi.org/10.1191/1478088706qp063oa

Brown, A. P. (2010). Qualitative method and compromise in applied social research. Qualitative Research, 10, 229-248.

Crotty, M. (1998). The foundations of social research: Meaning and perspective in the research process. Los Angeles, CA: Sage.

Dries, N., Pepermans, R., \& De Kerpel, E. (2008). Exploring four generations' beliefs about career: Is 'satisfied' the new 'successful'? Journal of Managerial Psychology, 23(8), 907-928. https://doi.org/10.1108/02683940810904394

Epstein, M., \& Hershatter, A. (2014). Millennials and the world of work: An organization and management perspective. Journal of Business and Psychology, 25(2), 211-223. https://doi.org/10.1007/s10869-010-9160-y

Eversole, B. A. W., Venneberg, D. L., \& Crowder, C. L. (2012). Creating a flexible organizational culture to attract and retain talented workers across generations. Advances in Developing Human Resources, 14(4), 607-625. https://doi. org/10.1177/1523422312455612

Fink, A. (2003). The survey handbook. Thousand Oaks, CA: Sage. https://doi. org/10.4135/9781412986281

Greenhaus, J. H., \& Allen, T. (2011). Work-family balance: A review and extension of the literature. In L. Tetrick \& J. C. Quick (Eds.), Handbook of occupational health psychology (2nd edn., pp. 165-183). Washington, DC: American Psychological Association.

Greenhaus, J. H., \& Kossek, E. E. (2014). The contemporary career: A workhome perspective. Annual Review of Organizational Psychology and Organizational Behavior, 1, 361-388. https://doi.org/10.1146/annurevorgpsych-031413-091324

Grimland, S., Vigoda-Gadot, E., \& Baruch, Y. (2011). Career attitudes and success of managers: The impact of chance event, protean, and traditional careers. The International Journal of Human Resource Management, 23(6), 1074-1094. https://doi.org/10.1080/09585192.2011.560884

Gunz, H. P., \& Heslin, P. A. (2005). Reconceptualizing career success. Journal of Organizational Behavior, 26(2), 105-111. https://doi.org/10.1002/job.300

Hall, D. T., Lee, M. D., Kossek, E. E., \& Heras, M. L. (2012). Pursuing career success while sustaining personal and family well-being: A study of reduced-load professionals over time. Journal of Social Issues, 68(4), 742-766. https://doi org/10.1111/j.1540-4560.2012.01774.x

Heslin, P. A. (2005). Conceptualizing and evaluating career success. Journal of Organizational Behavior, 26, 113-136. https://doi.org/10.1002/job.270

Jansen, H. (2010). The logic of qualitative survey research and its position in the field of social research methods [63 paragraphs]. Forum Qualitative Sozialforschung/ Forum: Qualitative Social Research, 11(2), Art. 11. Available from: http://nbn resolving.de/urn:nbn:de:0114-fqs1002110.

Judge, T. A., Cable, D. M., Boudreau, J. W., \& Bretz, R. D. (1995). An empirical investigation of the predictors of executive career success. Personnel Psychology, 48(3), 485-519. https://doi.org/10.1111/j.1744-6570.1995.tb01767.x 
Keeney, J., Boyd, E. M., Sinha, R., Westring, A. F., \& Ryan, A. M. (2013). From 'workfamily' to 'work-life': Broadening our conceptualization and measurement. Journal of Vocational Behavior, 82(3), 221-237. https://doi.org/10.1016/j.jvb.2013.01.005

Koekemoer, E., Fourie, H., \& Jorgensen, L. (2018). Exploring subjective career success among blue-collar workers: Motivators that matter. Journal of Career Development. https://doi.org/10.1177/0894845318763942

Kultalahti, S., \& LiisaViitala, R. (2015). Generation Y - Challenging clients for HRM Journal of Managerial Psychology, 30(1), 101-114.

Laufer, R. S., \& Bengtson, V. L. (1974). Generations, aging, and social stratification: On the development of generational units. Journal of Social Issues, 30, 181-205. https://doi.org/10.1111/j.1540-4560.1974.tb00733.x

Luscombe, J., Lewis, I., \& Biggs, H. C. (2013). Essential elements for recruitment and retention: Generation Y. Education and Training, 55(3), 272-290. https://doi. org/10.1108/00400911311309323

Lyons, S., \& Kuron, L. (2013). Generational difference in the workplace: A review of the evidence and directions for future research. Journal of Organizational Behavior 35, 139-157. https://doi.org/10.1002/job.1913

Lyons, S. T., Schweitzer, L., Ng, E. S. W., \& Kuron, L. K. J. (2012). Comparing apples to apples: A qualitative investigation of career mobility patterns across four generations. Career Development International, 17(4), 333-357. https://doi. org $/ 10.1108 / 13620431211255824$

Mainiero, L. A., \& Gibson, D. E. (2017). The Kaleidoscope Career Model revisited: How midcareer men and women diverge on authenticity, balance, and challenge. Journal of Career Development. https://doi.org/10.1177/0894845317698223

Mainiero, L. A., \& Sullivan, S. E. (2005). Kaleidoscope careers: An alternate explanation for the 'opt-out' revolution. Academy of Management Perspectives, 19(1), 106-123. https://doi.org/10.5465/AME.2005.15841962

Mayrhofer, W., Briscoe, J., Hall, D. T., Dickmann, M., Dries, N., Kaše, A. D. R., ... Unite, J. (2016). Career success across the globe: Insights from the 5 C project. Organizationa Dynamics, 45(2), 1-25. https://doi.org/10.1016/j.orgdyn.2016.07.005

Meriac, J. P., Woehr, D. J., \& Banister, C. (2010). Generational differences in work ethic: An examination of measurement equivalence across three cohorts. Journal of Business and Psychology, 25(2), 315-324. https://doi.org/10.1007/s10869-010-9164-7

Miles, M. B., \& Huberman, A. M. (1994). An expanded sourcebook: Qualitative dato analysis (2nd edn.). Thousand Oaks, CA: Sage.

Ng, E. S. W., Schweitzer, L., \& Lyons, S. T. (2010). New generation, great expectations: A field study of the Millennial generation. Journal of Business and Psychology, 25(2), 281-292. https://doi.org/10.1007/sl0869-010-9159-4

Ng, T. W. H., Eby, L. T., Sorensen, K. L., \& Feldman, D. C. (2005). Predictors of objective and subjective career success: A meta-analysis. Personnel Psychology, 58(2), 367-408. https://doi.org/10.1111/j.1744-6570.2005.00515.x

Onwuegbuzie, A. J., \& Leech, N. L. (2007). Sampling designs in qualitative research: Making the sampling process more public. The Qualitative Report, 22(2), 19-20. Available from: http://www.nova.edu/ssss/QR/QR12-2/onwuegbuzie1.pdf.
Papavasileiou, E. F., \& Lyons, S. T. (2015). A comparative analysis of the work values of Greece's 'Millennial' generation. The International Journal of Human Resource Management, 26(17), 2166-2186. https://doi.org/10.1080/095851 Resource Managen
92.2014 .985325

Parry, E., \& Urwin, P. (2011). Generational differences in work values: A review of theory and evidence. International Journal of Management Reviews, 23(1), 79-96. https:// doi.org/10.1111/j.1468-2370.2010.00285

Pilcher, J. (1994). Mannheim's sociology of generations: An undervalued legacy. British Journal of Sociology, 45(3), 481-495. https://doi.org/10.2307/591659

Ryan, R. M., \& Deci, E. L. (2000). Self-determination theory and the facilitation of intrinsic motivation, social development, and well-being. American Psychologist, 51(1), 68-78. https://doi.org/10.1037/0003-066X.55.1.68

Ryder, N. B. (1965). The cohort as a concept in the study of social change. American Sociological Review, 30, 843-861. https://doi.org/10.2307/2090964

Sparkes, A. C. (2002). Telling tales in sport and physical activity: A qualitative journey. Champaign, IL: Human Kinetics.

Suleman, R., \& Nelson, B. (2011). Motivating the millennials: Tapping into the potential of the youngest generation. Leader to Leader, 62, 39-44. https://doi. org/10.1002/ltl.491

Sullivan, S. E., \& Baruch, Y. (2009). Advances in career theory and research: A critical review and agenda for future exploration. Journal of Management, 35(6), 1542-1571. https://doi.org/10.1177/0149206309350082

Sullivan, S. E., Forret, M. L., Carraher, S. M., \& Mainiero, L. A. (2009). Using the kaleidoscope career model to examine generational differences in work attitudes. Career Development International, 14(3), 284-302. https://doi.org/10.1108/ 13620430910966442

Sullivan, S. E., \& Mainiero, L. (2008). Using the Kaleidoscope Career Model to understand the changing patterns of women's careers: Designing HRD programs that attract and retain women. Advances in Developing Human Resources, 10(1) 32-49. https://doi.org/10.1177/1523422307310110

Super, D. E. (1980). A life-span, life-space approach to career development. Journal of Vocational Behavior, 16(3), 282-298. https://doi.org/10.1016/0001-8791(80)90056-1

Terjesen, S., Vinnicombe, S., \& Freeman, C. (2007). Attracting generation Y graduates: Organisational attributes, likelihood to apply and sex differences. Caree Development International, 12(6), 504-522. https://doi.org/10.1108/136204 30710821994

Twenge, J. M. (2010). A review of the empirical evidence on generational differences in work attitudes. Journal of Business and Psychology, 25(2), 201-210. https://doi. org/10.1007/s10869-010-9165-6

Visagie, S., \& Koekemoer, E. (2014). What it means to succeed: Personal perceptions of career success held by senior managers. SA Journal of Business Management, 45(1), 43-54. https://doi.org/10.4102/sajbm.v45i1.116

Wayne, J. H., Butts, M. M., Casper, W. J., \& Allen, T. D. (2017). In search of balance: A conceptual and empirical integration of multiple meanings of work-family balance. Personnel Psychology, 70(1), 167-210. https://doi.org/10.1111/peps.12132 